\title{
CIENCIA VS. LENGUA. EL CATALÁN COMO LENGUA DE CIENCIA
}

Martí Domínguez

Universitat de València Director de Mètode 

George Steiner, en su libro Pasión intacta (1997), advierte del riesgo de utilizar una lengua minoritaria: «Por utilizar una frase de Henry James, ser escritor en una "lengua pequeña" significa tener "un destino complicado". No ser traducido, o incluso, no ser traducido al inglés, lo que significa ser olvidado». El inglés se ha convertido en la lingua franca del mundo y, como advierte Steiner, no ser traducido al inglés puede significar ser olvidado. En estos momentos, el inglés se ha convertido en la primera lengua de entre 350 a 500 millones de personas, y la segunda lengua de entre 200 y 600 millones de personas. Y en la lengua de uso habitual en las publicaciones científicas: en el Science Citation Index (sCI), donde se ordenan las distintas revistas en función de su índice de impacto, tienen muy poca cabida aquellas que no están íntegramente escritas en inglés. En 1995 el inglés era la lengua utilizada en el $95 \%$ de las revistas indexadas (alrededor de 8600), el resto del porcentaje estaba compuesto por revistas publicadas en francés, alemán, ruso y otras lenguas (un 0,5-0,7\% para este último grupo, donde se incluye el español) (Tardy, 2004).

El Science Citation Index es el instrumento habitualmente utilizado para valorar los currículos de los investigadores, por lo que publicar en revistas indexadas en este listado, y situadas en buena posición, resulta absolutamente necesario para la carrera del investigador. De este modo, no solo el conocimiento científico se expresa mayoritariamente en inglés, sino que el investigador que utiliza publicaciones no indexadas en el sci es penalizado, y pone en peligro su carrera científica.

Todo ello ha conducido a que en muy poco tiempo la mayor parte de las revistas hayan cambiado su registro lingüístico al inglés. Entre los años 1965 y 1988 el inglés aumentó y pasó del $50 \%$ al $64 \%$ en química, del $75 \%$ al $85 \%$ en biología y del 55\% al 82\% en matemáticas (Barraclough, 2009). En la actualidad, esta situación aún es mucho más acusada: el inglés es casi exclusivamente el único idioma de las publicaciones científicas de prestigio. Algunas revistas históricas, propias de instituciones culturales con una larga tradición, como Miscel.lània zoologica, que se empezó a publicar en el año 1958 por la Institució Catalana d'Història Natural, y que aceptaba artículos escritos en las principales lenguas europeas (además del catalán), empezó a publicarse íntegramente en inglés a partir del año 2001, con el título Animal Biodiversity and Conservation. Pero este no es un caso aislado, sino que más bien marca la tendencia actual: la revista Acta Geologica Hispanica, publicada por la Universitat de Barcelona desde 1966, adoptó el inglés como idioma exclusivo de su publicación el año 2003, y pasó a ser Geologica Acta. En otras ocasiones no fue necesario el cambio de nombre: 
la revista Thalassas, dedicada al estudio de la biología marina y publicada por la Universidade de Vigo, aceptaba artículos en las principales lenguas europeas y tiempo después se pasó íntegramente al inglés, pero conservaba su cabecera.

En estos momentos, los científicos espańoles publican fundamentalmente en esta lengua. Incluso en los congresos ibéricos presentan sus comunicaciones en inglés, ya preparadas para su publicación en una revista de referencia. Esta situación llevó al profesor Javier Ordóñez (2001) a escribir irónicamente: «El español es una lengua hablada por cuatrocientos millones de personas que parecen no querer hablar de ciencia». Pero esta anomalía (o diglosia) también se produce en Francia, Alemania e Italia, cuyos científicos han abandonado su lengua natal en el momento de difundir sus resultados. Si Albert Einstein publicó cuarenta y nueve artículos de física (entre ellos los cinco de 1905, su annus mirabilis) en la revista alemana Annalen der physics, y en alemán, ahora se vería obligado a hacerlo en inglés. El alemán era una lengua con un fuerte potencial científico, como recuerda Sir Peter Medawar, en su libro Consejos a un joven científico (2010): "A principios del siglo xx los jóvenes norteamericanos y británicos acudían en tropel a Alemania a iniciarse en la biología química avanzada. Nada ilustra más claramente este hecho que el estudio del alemán durante muchos años fue obligatorio para muchos aspirantes a químicos». No es necesario remarcar que ese ciclo se ha truncado por completo: ahora muy pocos científicos británicos estudian alemán (u otras lenguas), y concentran todo su tiempo y esfuerzo en la investigación.

El predominio del inglés es tan homogéneo y potente que prestigiosas editoriales científicas, como Elsevier, animan a los autores a someter sus artículos a una revisión por un inglés nativo antes de enviarlos para su evaluación. Y advierten: «los descubrimientos explicados en un artículo pueden ser de gran interés y actualidad, pero un lenguaje de mala calidad podría provocar la refutación del mismo». De este modo, el dominio del idioma (el inglés utilizado ha de ser propio de un «nativo») puede hacer peligrar unos resultados científicamente brillantes, incluso trascendentales para su área de investigación. John M. Swales (1997) habló en este sentido del inglés como un Tyrannosaurus rex: «un poderoso carnívoro que devora los bucólicos pastores de otros dominios lingüísticos». El trabajo de Swales desvela que la mayoría de los estudiantes no anglosajones piensan que el inglés no es una lengua neutral, aunque reconocen que, en cambio, puede ser de utilidad como lingua franca de la ciencia.

En cualquier caso, el reconocimiento académico y la promoción se miden en función de dónde se publica y la frecuencia con que lo hace un investigador. Para 
tener éxito se debe publicar en inglés, y esto representa un problema evidente para un gran número de científicos. Algunos centros de investigación disponen de gabinetes de traducción, otros contratan los servicios de un traductor, aunque todo ello no asegura una buena recepción: en ocasiones, un artículo revisado por «nativos» sigue ocasionando problemas lingüísticos al autor (el inglés de Norteamérica no es el mismo que el británico y son frecuentes correcciones estilísticas en función de la nacionalidad del revisor). En cualquier caso, los científicos angloparlantes nativos gozan de una clara ventaja respecto a los que no los son, y no solo porque tienen una mayor facilidad para presentar sus resultados, sino también porque a menudo actúan también de revisores de los trabajos enviados para su evaluación. En un estudio reciente se ha observado que los revisores de las revistas de gran impacto suelen ser angloparlantes; los de impacto medio, europeos, y los de impacto bajo, asiáticos o del resto del mundo (Ware y Monkman, 2008).

\section{CIENCIA VS. CULTURA CATALANA}

En el año 1994 se realizó en París un simposio titulado «Sciences et langues en Europe», en el que se constató el peligro de excluir la ciencia de la cultura de un país (Chartier y Corsi, 1994). La ciencia no es tan solo un conjunto de teorías, prácticas y aplicaciones, sino también un aspecto de la cultura contemporánea actual. En este simposio se llegó a tres conclusiones básicas:

1.- La lengua materna debe ser utilizada para transmitir los primeros conceptos científicos.

2.- La divulgación científica debe también realizarse en la lengua del país.

3.- Hay que hacer ciencia en la lengua del país.

La escolarización en la lengua materna y su uso para transmitir conceptos científicos resulta fundamental para la salud de una lengua. La ciencia es cultura y la cultura se expresa en una lengua: para la fortaleza de una cultura es fundamental que su uso se desarrolle en todos los ámbitos y, por tanto, también en el científico. La escolarización, la divulgación y la publicación de los resultados de la investigación se deberían realizar en la lengua del investigador, fuese cual fuese. Evidentemente, algunas lenguas son muy minoritarias, pero la mejor manera de conservarlas es cultivándolas con todo su potencial. Algunas consideraciones 
sostienen que el $80 \%$ de las 6000 lenguas vivas que existen en el mundo desaparecerán durante el siglo xxi. Sin duda, la mejor manera de evitar esta extinción y de preservar un patrimonio cultural de toda la humanidad es desarrollándolas en todas sus posibles facetas.

En estos momentos el catalán es una lengua hablada por alrededor de diez millones de personas. Es una lengua viva, con una larga y antigua tradición literaria. Asimismo, Cataluña es uno de los centros científicos más importantes de España, con un potencial universitario e investigador de primer orden. Por otro lado, el Institut d'Estudis Catalans (IEC) es una institución creada en 1907 y está organizada en cinco secciones, como el Institut de France; se trata de una federación que reúne 26 sociedades filiales con 8500 asociados y es uno de los principales motores culturales y científicos de Cataluña. Entre sus objetivos está normalizar el uso de la lengua catalana en el contexto científico. Ramon Aramon, presidente de honor del IEC, y filólogo de renombre, ya lo advirtió en su momento: «Para la normalidad de la cultura catalana, es más importante tener un libro de ciencia que diez novelas». L'iec publica un gran número de revistas científicas, aunque algunas de ellas directamente en inglés, como ocurre con Contributions to Science.

Curiosamente, el mayor peligro para la cultura catalana no es el español sino posiblemente el inglés. El Gabinet Lingüístic de la Universitat Pompeu Fabra, en su informe sobre las tesis leídas durante el periodo 1999-2010, muestra que el inglés es la lengua más utilizada: de un total de 746 tesis leídas, 333 fueron en inglés, 270 en español, 139 en catalán, 2 en francés y 1 en italiano. Resulta muy significativo como de las 200 tesis leídas en el departamento de Ciencias Experimentales y de la Salud la mitad (105) fueron en inglés. Todos estos datos, que se repiten aproximadamente en el resto de universidades catalanas, muestran el predominio cada vez más importante del inglés, que desbanca no solo al catalán sino también al castellano. En ocasiones, las nuevas revistas de las universidades catalanas nacen directamente en inglés, aunque su objetivo fundamental sea el estudio de la cultura catalana (un caso singular es Catalan Journal of Communication, que se centra principalmente en el estudio de los mass media catalanes y españoles).

Así las cosas, a un científico que se expresa en catalán le resulta casi imposible publicar su investigación en dicha lengua. La opción por el inglés (que no por el castellano) es la más frecuente. Sin embargo, acostumbra a realizar la divulgación científica en catalán: el área lingüística catalana dispone de buenas editoriales que facilitan ese trabajo de difusión (editoriales como Rubes, Bromera, Pòrtic, los 
servicios de publicaciones de las universidades, etc.). La cultura catalana también cuenta con revistas de divulgación (como Mètode o Omnis Cellula) o con potentes entramados museísticos que permiten la elaboración de simposios y cursos divulgativos (Cosmocaixa, Museu d'Història Natural, etc.). En este sentido, existe un abismo infranqueable entre la ciencia y su difusión: si la primera se publica mayoritariamente en inglés (en inglés científico, con un uso muy pobre de los recursos estilísticos), en cambio la segunda se lleva a cabo preferiblemente en la lengua materna y es donde el científico puede hacer gala de su cultura literaria.

En cualquier caso, quizá cuando el dominio del inglés sea mayor por parte de los investigadores, el paso siguiente será realizar también la divulgación en dicha lengua. Así como la docencia en los centros universitarios, con el uso de los libros de texto anglosajones. También se podría producir una escolarización en inglés de los alumnos de secundaria (que ya se realiza en numerosos centros privados, pero que también podría ser una realidad en la enseñanza pública, al menos con algunas asignaturas). De este modo, el entramado cultural de un país puede verse fuertemente influenciado por la cultura inglesa, en detrimento no solo de la lengua propia, sino de la pluralidad y diversidad lingüística europea.

Es posible que el conde de Buffon hubiera publicado hoy en día su Historia natural en inglés. Pero si la memoria de Buffon sigue tan viva no es tanto por sus descubrimientos científicos sino por su lengua: por su francés eterno. El idioma es consustancial a la ciencia, y forma también parte de la obra del científico. Galileo fijó el toscano, Buffon el francés, Darwin fue un excepcional retórico en lengua inglesa (Domínguez, 2011). Ninguno de estos científicos hubiera podido realizar su obra con tanto éxito si utilizaran una lengua extranjera: su dominio del idioma fue fundamental para su popularización y para su repercusión pública. La ciencia no tiene lengua, pero los científicos sí, por mucho que se intente obviar u ocultar. Y todo científico, desde el momento en que publica su obra en una lengua determinada, pertenece a la cultura de ese idioma: Einstein a la alemana, Darwin a la inglesa, Galileo a la italiana, Buffon a la francesa... Evidentemente, un científico, como un escritor, puede cultivar varias lenguas, pero siempre hay una que es con la que mejor se expresa. Por tanto, el catalán, como el resto de lenguas con un potencial científico importante, puede y debe ser una lengua de ciencia. Los científicos han de tener la posibilidad de expresarse en la lengua de su país y poder integrar la ciencia como un elemento más de su cultura. De lo contrario, la diglosia cada vez será mayor y, al final, la lengua más débil acabará por desaparecer. Y será una más de las que se extinguirá durante este siglo. 


\section{Bibliografía}

Barraclough, F.: «La "lingua franca” de la ciencia. El predomini de l'anglès en les publicacions científiques», Mètode, 62 (2009), pp. 27-31.

Chartier, R. y P. Corsi: Sciences et langues en Europe. Communications du colloque "Sciences et langues en Europe», París, 1994.

Domínguez, M.: «Darwin divulgador. La perfecció de l'ull com a metàfora literària», en Actes d'Història de la Ciència i de la Tècnica. Nova Ėpoca, vol. 3 (2011), pp. 153-179.

Medawar, P.: Consejos a un joven cientifico, Barcelona, Ed. Crítica, 2010.

Ordóñez, J.: El Español y la Ciencia. Congreso Internacional de la Lengua Española, Valladolid, 2001.

Steiner, G.: Pasión intacta, Barcelona, Siruela, 1997.

Swales, J. M.: «English as Tyrannosaurus rex», World Englishes, 16: 3 (1997), pp. 373-382.

TARdy, C.: «The role of English in scientific communication: lingua franca or Tyrannosaurus rex?», Journal of English for Academic Purposes, 3 (2004), pp. 247-269.

Ware, M. y M. Monkman: Peer Review in Scholarly Journals. Perspective of the scholarly community: an international study, Mark Ware Consulting, 2008. 